\title{
Use of CCW (Civil Construction Waste) in Soil
}

\section{Improvement}

\author{
Andréa Batista de Farias, Stela Paulino Fucale and Alexandre Duarte Gusmão
}

Department of Civil Engineering, University of Pernambuco, Recife/PE 50 720-410, Brazil

\begin{abstract}
The vast production of CCW (Civil Construction Waste) has caused socio-environmental concern as a result of the exploration of natural resources, clandestine disposal and proliferation of vector-borne diseases, for example. It now gives priority to non-generation, reduction and recycling of CCW. This study, therefore, seeks an alternative for CCW by comparing the physical and mechanical characteristics, both in laboratory and onsite, of the recycled CCW aggregate and natural aggregate (stone powder), commonly used in the composition of compaction piles for improving soils in foundation works in the city of Recife, Pernambuco, Brazil. All results showed similar behaviours among the investigated samples (CCW recycled and natural), confirming the satisfactory performance of the investigated CCW material.
\end{abstract}

Key words: Civil construction waste, recycled aggregate, soil improvement.

\section{Introduction}

Although civil construction is a sign of a country's development, since investments in the sector have risen from 168 billion BRL in 2005 to $\$ 259$ billion of reals in 2008, jobs have increased by around $20 \%$ in those years and the Brazilian GDP (gross domestic product) rose $27 \%$ in real terms [1], its major problem lies in high CCW production, representing an average of 300-500 kg/inhab·year [2].

The absence of a public policy, lack of commitment of CCW producers and collectors and the public's lack of environmental consciousness are responsible for illegal refuse dumps and disposal that consequently cause environmental impacts, such as proliferation of vector-borne diseases, sedimentation of rivers and creeks, obstruction of drainage systems and so on.

On the other hand, frontline technologies have appeared in various branches of civil engineering to attempt to absorb CCW as low-cost recycled material, such as, for example, paving, concrete with no structural function, drainage layers, soil improvement

Corresponding author: Andréa Batista de Farias, M.Sc., research field: civil construction waste management. E-mail: abf_pec@poli.br. and so on. Paving in the city of São Paulo using recycled aggregate as substitute for the conventional material cut the cost by $18 \%$ [3].

Concerning improvement of sandy soils, the city of Recife, capital of Pernambuco State (Northeast Brazil), where this study was undertaken, has morphologically two types of landscape: hills and plains [4].

The former are on the periphery and simple light buildings predominate. The plains, however, characterized by large constructions consist mostly of sandy layers.

In coastal towns in Northeast Brazil the use of compaction piles is current practice using the vibro-displacement technique as a method for improving sandy soil in shallow slab foundations [5]. Compaction piles increase the load capacity of the soil and reduce foundation settlements, so that the choice of direct foundations is technical and economically feasible.

Some types of compaction piles worth mentioning are: (1) sand and crushed stone piles, (2) cement and sand piles and (3) cement, crushed stone and sand piles. It is worth pointing out that in Recife, Pernambuco, it is common to substitute sand for stone 
dust as fill material for these piles. When undertaking sand and crushed stone compaction piles they are introduced into the surface layers of the soil through a metal pipe with a dry plug at the end as far as the layer to be compacted. Next, the plug is removed and sand and crushed stone in a 3:1 proportion are inserted into the pipe. Dynamic energy is applied due to the tamping freefall to the desired compactness. The pipe is then raised and the technique is progressively adopted for the upper layers until reaching ground level, as shown in the diagram in Fig. 1.

In the light of the above, this article not only analyses or performs the recycled $\mathrm{CCW}$ aggregate, but also investigates natural aggregate (stone dust) to give a better comparison and assessment between the two materials.

\section{Laboratory and Onsite Investigation}

The first experimental stage of the study consisted of laboratory tests involving studies on the gravimetric composition, characterization, compaction and direct shear of the natural aggregate and recycled $\mathrm{CCW}$ aggregate. In the second stage, onsite tests were performed, that is, boreholes SPT (Standard Penetration Test) within and outside the site where piling was undertaken for soil improvement, on terrain in the city of Recife, Pernambuco. A plate load test on compaction piles located in an experimental mesh on the investigated land and virgin soil was also carried out using recycled $\mathrm{CCW}$ aggregate and natural aggregate (stone dust).

\subsection{Collecting Samples}

The CCW sample was obtained from a jobsite in the city of Recife (Pernambuco), which had a waste management system, where the job was in the final stage and with internal masonry with structural beam reformulation. After collecting around five tonnes of $\mathrm{CCW}$, this material underwent tactile-visual separation, followed by processing, and diminishing the size of the grains $(\varnothing \leq 4.8 \mathrm{~mm})$. The natural

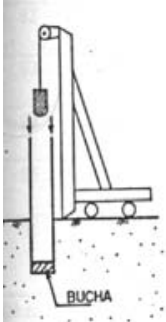

(A)

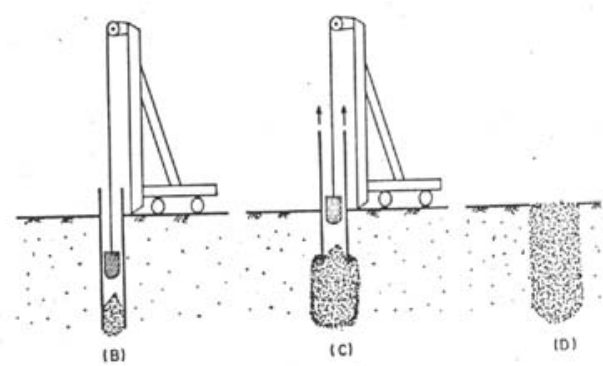

(D)
Fig. 1 Driving compaction piles [4].

aggregate on the other hand was procured from a job that was using the compaction pile technique for soil improvement in Recife.

\subsection{Laboratory Tests}

\subsubsection{Characterisation and Compaction Tests}

The characterization tests carried out on the natural and recycled (CCW) aggregates were particle size, consistency limits and actual density. A compaction test was also performed using the normal Proctor energy, all conforming to the ABNT (Brazilian Association of Technical Standards).

\subsubsection{Direct Shear Tests}

In the case of the direct shear test, a velocity of 0.31 $\mathrm{mm} / \mathrm{min}$ and normal stresses of 50, 100, 150 and 200 $\mathrm{kPa}$ were adopted in the two samples. The fast test was done using moulded samples in the condition of optimum moisture, measuring shear stress $(\tau)$ and horizontal displacements $(\mathrm{mm})$ undergone by the materials under certain normal stresses $(\sigma)$.

\subsection{Onsite Tests}

2.3.1 SPT Within and Outside the Experimental Mesh

SPTs were performed to discover the layout, nature and thickness of the soil layers; penetration resistance, compressibility and settlement of the soil.

To assess the technical feasibility of the use of $\mathrm{CCW}$ onsite an experimental mesh was adopted with 25 piles in the ground, 19 of which were conventional, that is, with stone dust; and six with recycled material (CCW), at a depth of between $3.5 \mathrm{~m}$ and $5 \mathrm{~m}$ (Figs. 2-3). 
The boreholes analysed in the SPT tests outside but close to the mesh were SP 01, SP 02 and SP 03. SP 07 and SP 08 boreholes inside the mesh were also analysed. It must be mentioned that the SP 08 borehole was carried out between compaction piles of recycled material (E12, E13, E17 and E18), while borehole SP 07 was driven between piles E8, E9, E13 and E14, two consisting of $\mathrm{CCW}$ and two of natural aggregate.

\subsubsection{Plate Load Test}

The purpose of this plate LT (load test) method on a pile is to provide elements to assess its load versus displacement behaviour, and to estimate its load capacity characteristics.

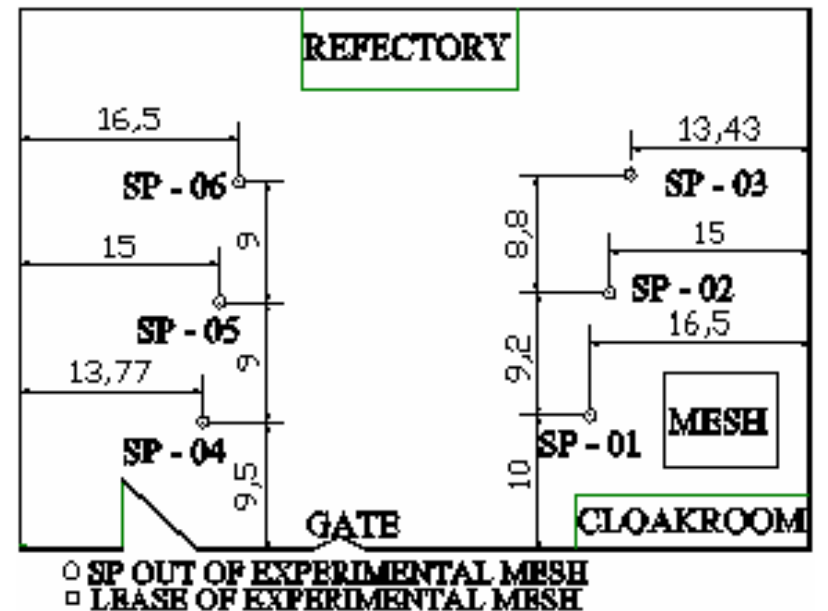

Fig. 2 Ground plan of site.

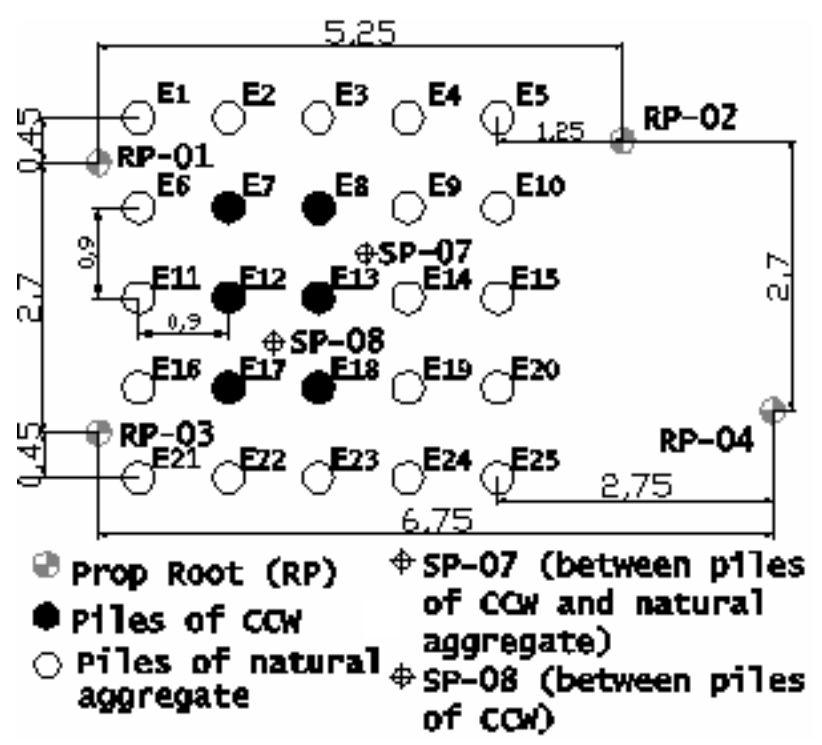

Fig. 3 Ground plan of experimental mesh.
Fifteen load tests were carried out during the entire experimental study, three of which are analysed in this article. The load test on pile E8 (CCW) was referred to as LT 09, on pile E9 (conventional) was LT 08 and on virgin soil (outside the experimental mesh) was LT 11. All tests were fast, with readings at 0,2 and 5 minutes using plates $300 \mathrm{~mm}$ in diameter.

\section{Results}

\subsection{Gravimetric Composition}

After tactile-visual segregation and weighing, it was possible to determine the gravimetric composition of the investigated CCW sample shown in Fig. 4.

On analysing Fig. 4, the predominance of concrete $(60 \%)$ is visible in relation to the other elements, justified by the fact that when collecting this material a beam was being reformulated. The presence of materials is visible, such as plastic, paper, metal, called "others" in this study, and later segregated, since this study only addresses waste that can be used as recycled aggregates.

\subsection{Characterisation and Compaction}

After performing this test it was possible to prepare the grading curves of the recycled $\mathrm{CCW}$ sample and the natural aggregate (Fig. 5). It is found that the samples studied consist mainly of classified materials, such as a sand fraction, and also show a small percentage of silt and clay fractions.

Based on the actual density test, similarity was found between the two materials studied, with the following values of 2.69 and 2.67 for stone dust and the $\mathrm{CCW}$ sample, respectively. These values are typical of granular materials (sandy).

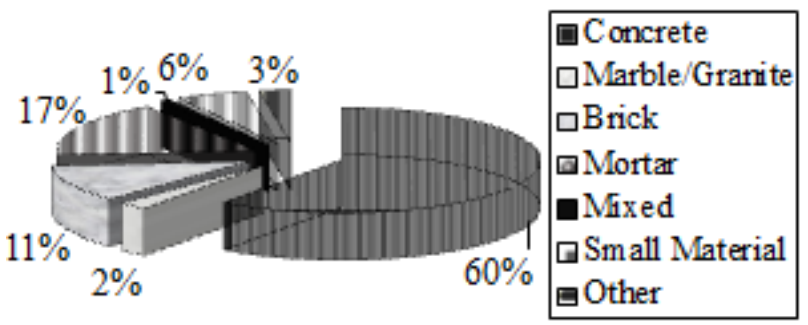

Fig. 4 Gravimetric composition of the elements in the 
sample under analysis.

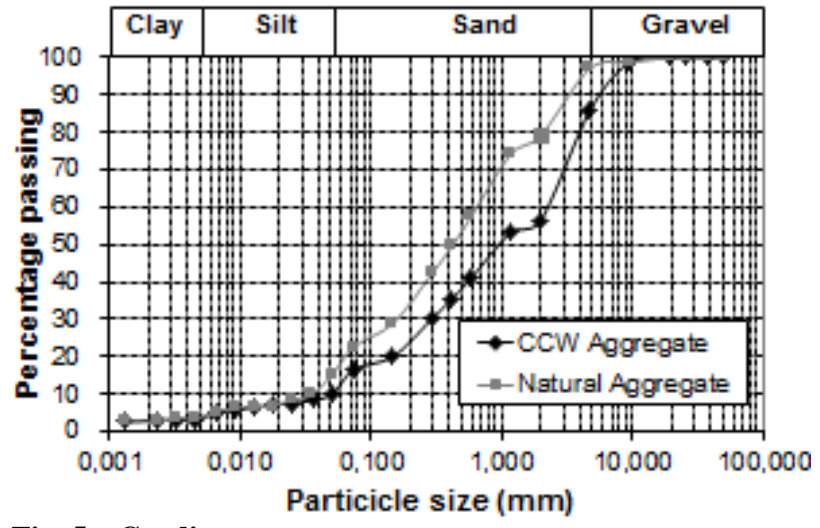

Fig. 5 Grading curves.

With regard to consistency limit tests, the $\mathrm{CCW}$ sample and natural aggregate did not show LL (liquid limit), plastic limit and shrinkage limit.

Fig. 6 shows the compaction curves for both the $\mathrm{CCW}$ recycled sample and stone dust.

With the results of the compaction test in hand, optimum moistures $17.5 \%$ and $9.8 \%$ and maximum dry apparent specific mass of 16.8 and $20.3 \mathrm{kN} / \mathrm{m}^{3}$ were obtained for the recycled material and stone dust, respectively. The values found for dry apparent specific mass of the $\mathrm{CCW}$ in accordance with its gravimetric compositions were $17.5 \mathrm{kN} / \mathrm{m}^{3}$ and 16.6 $\mathrm{kN} / \mathrm{m}^{3}$, in others studies $[6,7]$. In a comparative analysis similarity was noted between the data obtained in this study and in investigations made by other authors.

\subsection{Direct Shear Strength}

The result obtained from the direct shear test of both samples investigated in the condition of optimum moisture showed that the recycled material had more strength than the stone dust, since the former presented an angle of friction of $45.2^{\circ}$ and the latter $22.5^{\circ}$.

In investigations carried out on recycled civil construction waste materials, with a gravimetric composition showing concrete (42\%) and brick (49\%) as the main elements, the value for the angle of friction was $38.0^{\circ}$ and $46.7^{\circ}[8,9]$. It should also be mentioned that these results are close to those

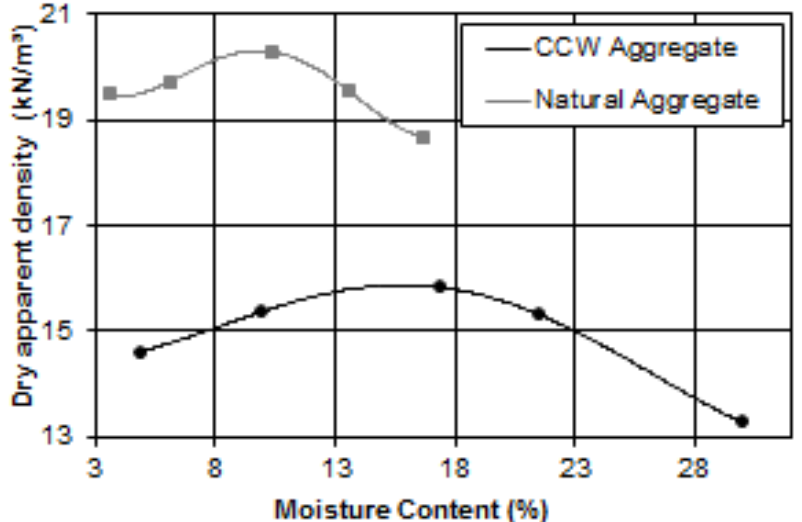

Fig. 6 Compaction curves of the CCW sample and natural aggregate.

obtained in studies on angular, compact and well-graded sand $\left(45^{\circ}\right)[10]$.

\subsection{Borehole (SPT)}

By performing the SPT outside the experimental mesh it was possible to determine the typical profile of the subsoil in the investigated area, and the natural soil penetration resistance (without improvement).

According to Fig. 7, the depth reached by the tests was approximately $23 \mathrm{~m}$. Fine and medium sand is found down to the first five metres. At greater depths,

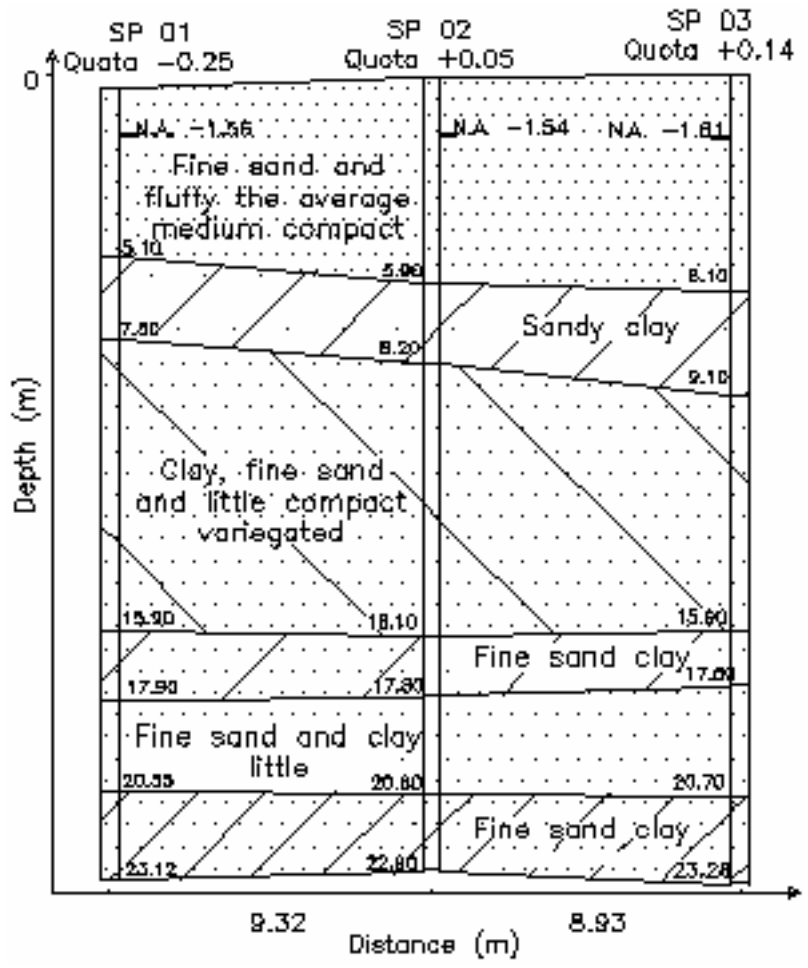

Fig. 7 Profile of the subsoil. 
the layers consist mainly of clayey fine sand, also with a clay layer with an average thickness of $2.5 \mathrm{~m}$. The $W L$ (water level) is around $1.57 \mathrm{~m}$ from the surface. It is also found that existing sand layers have characteristics varying from fluffy to only slightly compact.

The boreholes outside the mesh were $23 \mathrm{~m}$ in depth to be able to know the ground profile and resistance. After piling, other boreholes were drilled to determine the gain in resistance within the mesh.

Data were compiled to compare the resistances in and outside the experimental mesh (Fig. 8).

Fig. 8 shows that the maximum blows in the three boreholes outside the mesh were 14, 17 and 16, respectively, while in the mesh they were 24 and 23 for SP 07 and SP 08. And when comparing SP 03 (outside the mesh) with SP 08 (inside the mesh) to a depth of $2.5 \mathrm{~m}$, further resistance of $475 \%$ was found. It is stressed that SP 08 was drilled between compaction piles, as explained in item SPT within and outside the experimental mesh.

\subsection{Load Test}

To confirm the satisfactory behaviour of the piles and determine successive settlements, piles E8 (CCW) and E9 (natural aggregate) and the virgin soil were loaded progressively (Fig. 9).

With the results obtained from the load test, the $\mathrm{CCW}$ pile was found to perform well in comparison

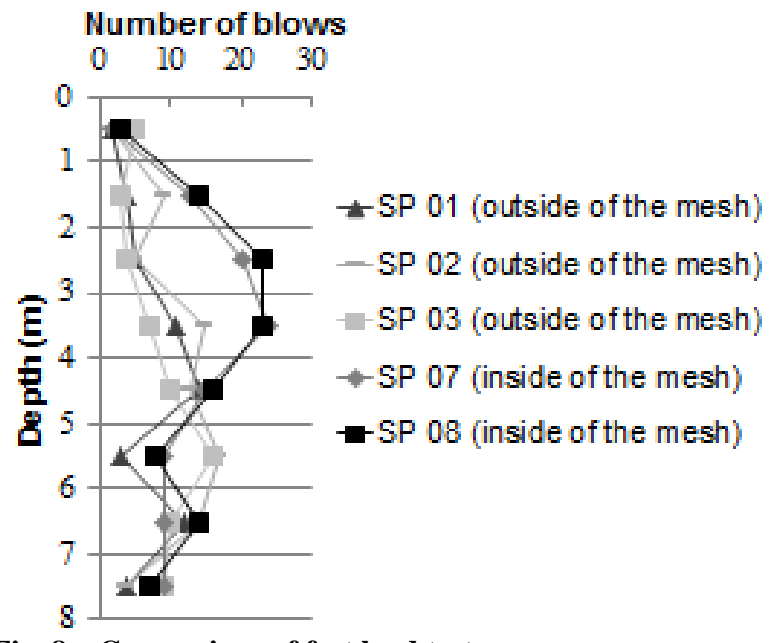

Fig. 8 Comparison of fast load tests.

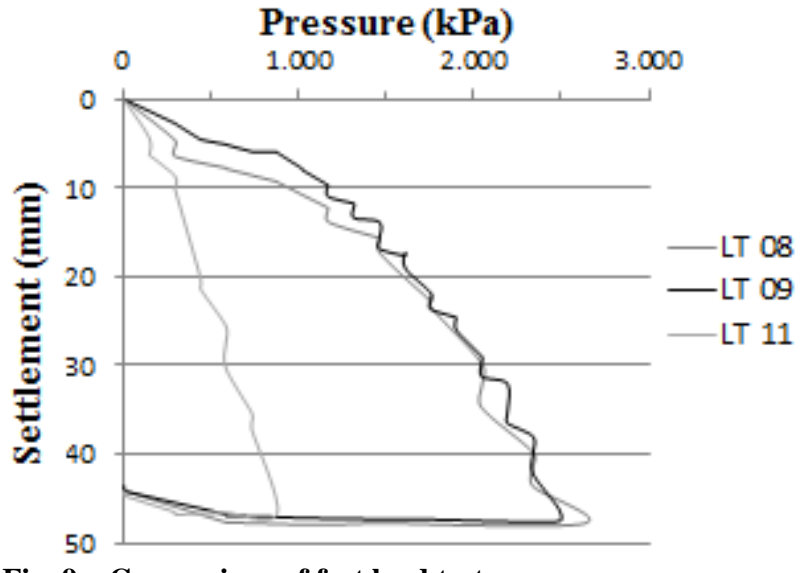

Fig. 9 Comparison of fast load tests.

with the conventional piles (with natural aggregate). The maximum values achieved in LT 08, LT 09 and LT 11 were $2628.53 \mathrm{kPa}, 2482.82 \mathrm{kPa}$ and $877.12 \mathrm{kPa}$, respectively (Table 1).

Based on the natural aggregate pile in Table 1, the performance of the other two plate load tests can be compared based on the pressure it withstands. According to the full study of the tests, the majority of results of the $\mathrm{CCW}$ and natural aggregate piles were similar, which is an excellent finding for the feasibility of this material. It is also found that the behaviour between the two load tests LT 08 and LT 09 and the low stress value borne by the virgin soil is compatible.

Table 1 Results of the plate load tests.

\begin{tabular}{|l|l|l|l|}
\hline Load test & LT 08 & LT 09 & LT 11 \\
\hline Material & $\begin{array}{l}\text { Natural } \\
\text { aggregate } \\
\text { (E9) }\end{array}$ & $\begin{array}{l}\text { CCW } \\
\text { aggregate } \\
\text { (E8) }\end{array}$ & $\begin{array}{l}\text { Virgin } \\
\text { soil }\end{array}$ \\
\hline Pressure $(\mathrm{kPa})$ & 2628.53 & 2482.82 & 877.12 \\
\hline Settlement (mm) & 47.82 & 47.59 & 46.73 \\
\hline $\begin{array}{l}\text { Percentage based } \\
\text { on the pressure } \\
\text { withstood by } \\
\text { natural aggregate } \\
\text { pile }\end{array}$ & $100 \%$ & $94.46 \%$ & $33.37 \%$ \\
\hline
\end{tabular}

\section{Conclusions}

In the light of the above, it is concluded that there is a technical similarity in the characteristics of the civil construction waste investigated in this study and natural aggregate (stone dust). Very positive results 
were achieved in both the laboratory and onsite tests, which showed high potential for using recycled CCW as an alternative material for compaction piles in foundation jobs for soil improvement. In short, this study indicates yet another possibility for using CCW by the civil construction industry, helping to adapt it to the environmental context and conform to sustainability development by recycling, reducing the proliferation of vector-borne diseases, illegal disposal and environmental pollution.

\section{Acknowledgments}

The authors would like to thank to CNPq, FACEPE and POLI/UPE for the financial support for the research.

\section{References}

[1] F. Buzzo, Abramat and FGV/projects demonstrate the importance of the sector to the Brazil and real impacts of the crisis on the activity, available online at: http://www.abramat.org.br/files/090914_NotaTecnica_Ca deiaProdutiva.pdf.

[2] A. D. Gusmão, Waste Management Manual of Civil Construction, Graphic Publisher, Recife/PE, 2008.
[3] R. S. Motta, Laboratory study of household solid waste recycled construction for application in low-traffic paved, Master Thesis, Polytechnic School, University of São Paulo, 2005, p. 160.

[4] A. D. Gusmão, J. A. G. Filho, J. T. R. de Oliveira and G. B. Maia, Improvement of sandy land, Geotechnical in Northeast, Recife (Vol. 1), Pernambuco Federal University Press, 2005, pp. 331-363.

[5] W. C. Soares, Piles of compression for soil improvement, Master Thesis, Postgraduate Programme of the São Carlos School of Engineering, University of São Paulo, São Paulo, 2002.

[6] R. A. Medeiros Junior, Use of Recycled Aggregate from Construction Waste for the production of Mortar with Use in Compression Stakes, Report of Pibic Scientific Initiation/UPE, Recife/PE, 2008.

[7] E. L. Araújo Junior, Construction and demolition waste (CDW) use in compaction piles for soil improvement, Master Thesis, Civil Engineering Post-graduate Program, Pernambuco Polytechnic, University of Pernambuco, Recife, 2009, p. 156. (CD ROM)

[8] T. C. R. Silva, Application of Construction Waste as Fill Material in Compacting Piles, University of Pernambuco, Course completion work, Recife/PE, 2009.

[9] M. A. B. Silva Junior, Use of Debris from Construction and Demolition Benefited as Material for Covering of Landfills in the Metropolitan Region of Recife, Report of Pibic Scientific Initiation/UPE, Recife/PE, 2009.

[10] T. W. Lambe and R. V. Whitman, Soil Mechanics, John Willey \& Sons, New York, 1979. 